\title{
The use of predefined diet quality scores in the context of CVD risk during urbanization in the South African Prospective Urban and Rural Epidemiological (PURE) study
}

\author{
Robin C Dolman ${ }^{1, *}$, Edelweiss Wentzel-Viljoen ${ }^{1}$, Johann C Jerling ${ }^{1}$, Edith JM Feskens ${ }^{2}$, \\ Annamarie Kruger $^{3}$ and Marlien Pieters ${ }^{1}$ \\ ${ }^{1}$ Centre of Excellence for Nutrition (CEN), North West University, Potchefstroom, 2520 South Africa: ${ }^{2}$ Division of \\ Human Nutrition, Wageningen University, Wageningen, The Netherlands: ${ }^{3}$ Africa Unit for Trans disciplinary \\ Health Research (AUTHeR), North West University, Potchefstroom, South Africa
}

Submitted 21 September 2012: Final revision received 15 May 2013: Accepted 21 July 2013: First published online 19 August 2013

\begin{abstract}
Objective: Urbanization is generally associated with increased CVD risk and accompanying dietary changes. Little is known regarding the association between increased CVD risk and dietary changes using approaches such as diet quality. The relevance of predefined diet quality scores (DQS) in non-Western developing countries has not yet been established.

Design: The association between dietary intakes and CVD risk factors was investigated using two DQS, adapted to the black South African diet. Dietary intake data were collected using a quantitative FFQ. CVD risk was determined by analysing known CVD risk factors.

Setting: Urban and rural areas in North West Province, South Africa.

Subjects: Apparently healthy volunteers from the South African Prospective Urban and Rural Epidemiological (PURE) study population ( $n$ 1710).

Results: CVD risk factors were significantly increased in the urban participants, especially women. Urban men and women had significantly higher intakes of both macro- and micronutrients with macronutrient intakes well within the recommended CVD guidelines. While micronutrient intakes were generally higher in the urban groups than in the rural groups, intakes of selected micronutrients were low in both groups. Both DQS indicated improved diet quality in the urban groups and good agreement was shown between the scores, although they seemed to measure different aspects of diet quality.

Conclusions: The apparent paradox between improved diet quality and increased CVD risk in the urban groups can be explained when interpreting the cut-offs used in the scores against the absolute intakes of individual nutrients. Predefined DQS as well as current guidelines for CVD prevention should be interpreted with caution in non-Western developing countries.
\end{abstract}

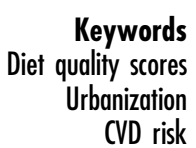

In developing countries, the process of urbanization and modernization of lifestyles has marked effects on populations. While still battling infectious diseases, these countries are also facing an increase in non-communicable diseases $^{(1)}$. With urbanization in low- and middle-income countries there is an increase in socio-economic status, which is usually accompanied by an increase in most risk factors for $\mathrm{CVD}^{(2)}$. These risk factors include obesity and increased dietary intakes of total fat and saturated fat, as has been observed in the North West Province of South Africa in the Transition and Health during Urbanization in South Africans (THUSA) study ${ }^{(3)}$, as well as in other developing countries ${ }^{(4)}$. Among numerous other factors, this increase in CVD risk has been ascribed to a worsening diet in populations as they transition from a rural to an urban lifestyle. Traditionally, in South Africa, the diet was low in fat and sugar and rich in fibre ${ }^{(5)}$. Due to urbanization and the resultant increase in socio-economic status, the diet now tends to be richer in animal products, refined grains, fats, salt and sugar, and lower in fibre ${ }^{(3,6)}$.

Until now, the effect of urbanization on diet has been investigated by looking mostly at the nutrient composition of diets. However, the failure of single-nutrient supplementation to protect against $\mathrm{CVD}^{(7)}$ and cancers ${ }^{(8,9)}$ highlighted the fact that it was important to develop a more holistic view of food intake. Foods are biochemically complex and contain compounds that may interact with each other. By investigating not only nutrients but also 
foods and dietary quality, the complexity of dietary behaviours and interactions are taken into account. One way of assessing dietary quality is to use theoretically defined dietary patterns that are based on current nutrition knowledge. These theoretical or predefined diet quality scores (DQS) consist of foods and/or nutrients which are considered to be important to health ${ }^{(10)}$.

In a critical review of predefined DQS, Waijers et al. $(2007)^{(10)}$ made recommendations regarding the decisions that need to be made when constructing a DQS. It is advised that a score should contain two macronutrients (fat, carbohydrate or protein) to ensure overall balance. It is also desirable to let the score be proportional to intake, instead of using simple cut-off values, or else to design a scoring range. To avoid confounding by energy intake, scores should depend on or be adjusted for energy intake. Another important issue to be taken into account is that food intake is culturally determined and therefore general dietary habits within the population being studied need to be considered when the score items and their cut-offs are chosen. The score should also be constructed in such a way that an acceptable dietary variety is ensured of obtaining a high score, but variety does not necessarily have to be included as a score item. It is also advisable to select more than one score when evaluating diet quality ${ }^{(11)}$.

Using these criteria, two scores were selected from the numerous available DQS to assess diet quality in our study population. The first is a score developed by Thiele et $a l .{ }^{(12)}$ which was adapted to the South African diet and renamed the Adapted Thiele Score (see 'Materials and methods' section for more details); the second is the Healthy Diet Indicator (HDI) ${ }^{(13)}$. The rationale for electing to use these specific DQS over the other known scores is that not only nutrients but also food groups are included, and that diet quality is assessed in relation to known and proven dietary guidelines specifically for the prevention of CVD. It will also be relatively simple to fit South African foods into the food groups used in these scores.

The aim of the present study was therefore to relate the dietary intakes of the South African Prospective Urban and Rural Epidemiological (PURE) study population ( $n$ 2010) using both nutrient intakes and diet quality, to CVD risk associated with urbanization. The PURE study is a large-scale cohort study that tracks changing lifestyles, risk factors and chronic disease using periodic standardized data collection in urban and rural areas of seventeen countries in transition ${ }^{(14)}$.

\section{Materials and methods}

The present study used baseline data collected over a 12-week period in 2005, from 2010 randomly selected volunteers in the South African arm of the PURE study. The study was conducted according to the guidelines laid down in the Declaration of Helsinki and all procedures involving human volunteers were approved by the Ethics Committee of the North West University, South Africa (No. 04M10). The volunteers signed informed consent before commencement of the study, after the study was explained to them in their home language. All data were treated confidentially and all analyses were performed with coded data. Black South African men ( $n$ 750) and women ( $n$ 1260) older than 35 years were recruited from 6000 randomly selected households. From these households, 1006 volunteers were recruited from rural (living under tribal law) and 1004 from urban areas (living in informal and formal settlements surrounding cities) in the North West Province of South Africa. Volunteers were included if they were apparently healthy. Exclusion criteria were the use of chronic medication for noncommunicable diseases and/or any self-reported illness. For various reasons dietary intake and anthropometric data could not be collected from some volunteers, who were consequently excluded from the data set, resulting in the total study population of 1710 .

Details regarding the collection of socio-economic information, anthropometry measurements, blood collection, blood pressure and physical activity have been reported previously $^{(15-17)}$.

A culturally sensitive quantitative (QFFQ) was completed by trained field workers in the respondents' language of choice. The QFFQ with good reproducibility ${ }^{(18)}$ was previously developed ${ }^{(19)}$ and validated in this population using $7 \mathrm{~d}$ weighed records and biomarkers ${ }^{(20)}$. Portion sizes were estimated using food portion photographs ${ }^{(21)}$, appropriate utensils and containers and examples of specific foods. Portion sizes were reported in household measurements and converted to weights using standard tables ${ }^{(22)}$. The QFFQ was completed for foods eaten over the previous $30 \mathrm{~d}$. The food intake was coded according to the South African Food Composition Database System of the South African Medical Research Council and then used to calculate the nutrient and food group intakes ${ }^{(23-25)}$.

\section{Diet quality scores}

Table 1 presents the components and cut-off points of the $\mathrm{HDI}^{(13)}$ and the Deficiency Score/Excess Score by Thiele et $a l^{(12)}$, which were used in the present study. The score by Thiele et al. suggested using up to thirty nutrients in a Deficiency Score to identify a preferable diet quality and using six nutrients in an Excess Score to identify a nonpreferable diet quality. After assessing the completeness of the relevant micronutrients in the South African Food Composition Database System, nineteen nutrients were used for the Deficiency Score in the present study and the suggested six were used for the Excess Score. The Estimated Average Requirement (EAR) or Adequate Intake (AI), when an EAR was not available, was used as cut-off points in the score ${ }^{(26-30)}$. Intake was then calculated as a percentage of the EAR or AI. Intake equal to or higher 
Table 1 Components of diet quality scores

\begin{tabular}{|c|c|c|c|c|}
\hline \multirow[b]{2}{*}{ Nutrient or food group (daily intake) } & \multirow[b]{2}{*}{ Units } & \multirow[b]{2}{*}{ Age (years) } & \multicolumn{2}{|c|}{ Cut-off values } \\
\hline & & & Men & Women \\
\hline \multicolumn{5}{|l|}{ Healthy Diet Indicator ${ }^{(13)}$} \\
\hline SFA ${ }^{*}$ & g & & $<10$ & $<10$ \\
\hline PUFA $^{*}$ & $\mathrm{~g}$ & & $6-10$ & $6-10$ \\
\hline Protein* & $\%$ TЕ & & $10-15$ & $10-15$ \\
\hline Complex carbohydrates* & $\%$ TE & & $50-70$ & $50-70$ \\
\hline Dietary fibre* & g & & $>25$ & $>25$ \\
\hline Fruit and vegetables* & $\mathrm{g}$ & & $>400$ & $>400$ \\
\hline Pulses, nuts and seeds* & $\mathrm{g}$ & & $>30$ & $>30$ \\
\hline Mono- and disaccharides* & $\%$ TЕ & & $<10$ & $<10$ \\
\hline Cholesterol* $^{*}$ & $\mathrm{mg}$ & & $<300$ & $<300$ \\
\hline \multicolumn{5}{|l|}{ Deficiency Score ${ }^{(12)}$} \\
\hline Proteint & $\%$ TE & & 15 & 15 \\
\hline Carbohydratet & $\%$ TE & & 55 & 55 \\
\hline Total fibre & g & $\begin{array}{l}<51 \\
>51\end{array}$ & $\begin{array}{l}38 \\
30\end{array}$ & $\begin{array}{l}25 \\
21\end{array}$ \\
\hline \multirow[t]{2}{*}{ Cał } & $\mathrm{mg}$ & $19-50$ & 1000 & 1000 \\
\hline & & $>51$ & 1200 & 1200 \\
\hline $\operatorname{Mg} \S$ & $\mathrm{mg}$ & $>31$ & 350 & 265 \\
\hline \multirow{2}{*}{ Fe§ } & $\mathrm{mg}$ & $31-50$ & $6 \cdot 0$ & $8 \cdot 1$ \\
\hline & & $>50$ & $6 \cdot 0$ & $5 \cdot 0$ \\
\hline $\mathrm{Zn} \S$ & $\mathrm{mg}$ & $>31$ & $9 \cdot 4$ & $6 \cdot 8$ \\
\hline Mn‡ & $\mathrm{mg}$ & $>31$ & $2 \cdot 3$ & $1 \cdot 8$ \\
\hline $\mathrm{K} \ddagger$ & $\mathrm{mg}$ & $>31$ & 4700 & 4700 \\
\hline Cuß & $\mu \mathrm{g}$ & $>31$ & 700 & 700 \\
\hline Vitamin $A \S$ & $\mu g$ & $>31$ & 625 & 500 \\
\hline Thiamin§ & $\mathrm{mg}$ & $>31$ & $1 \cdot 0$ & 0.9 \\
\hline Riboflavin§ & $\mathrm{mg}$ & $>31$ & $1 \cdot 1$ & 0.9 \\
\hline Niacin§ & $\mathrm{mg}$ & $>31$ & 12 & 11 \\
\hline \multirow[t]{2}{*}{ Vitamin $B_{6} \S$} & $\mathrm{mg}$ & $31-50$ & $1 \cdot 1$ & $1 \cdot 1$ \\
\hline & & $>51$ & $1 \cdot 4$ & $1 \cdot 3$ \\
\hline Folate§ & $\mu \mathrm{g}$ & $>31$ & 320 & 320 \\
\hline Vitamin $\mathrm{B}_{12} \S$ & $\mu \mathrm{g}$ & $>31$ & $2 \cdot 0$ & $2 \cdot 0$ \\
\hline Pantothenic acidł & $\mathrm{mg}$ & $>31$ & $5 \cdot 0$ & $5 \cdot 0$ \\
\hline Vitamin C§ & $\mathrm{mg}$ & $>31$ & 75 & 60 \\
\hline \multicolumn{5}{|l|}{ Excess Score ${ }^{(12)}$} \\
\hline Total fat ${ }^{\star}$ & $\%$ TE & & 30 & 30 \\
\hline Saturated:unsaturated fatty acids & & & $1: 2$ & $1: 2$ \\
\hline Cholesterol* $^{*}$ & $\mathrm{mg}$ & & $<300$ & $<300$ \\
\hline Alcohol\| & $\mathrm{g}$ & & 30 & 15 \\
\hline Added sugar ${ }^{*}+$ & $\%$ TE & & 10 & 10 \\
\hline \multirow[t]{2}{*}{ Nał } & $\mathrm{mg}$ & $31-50$ & 1500 & 1500 \\
\hline & & $>51$ & 1300 & 1300 \\
\hline
\end{tabular}

$\%$ TE, percentage of total energy (excluding energy from alcohol).

${ }^{*}$ Criteria used for cut-off values are WHO guidelines for prevention of chronic disease ${ }^{(34)}$

tDietary reference intake: Acceptable Macronutrient Distribution Ranges ${ }^{(30)}$.

fDietary reference intake: Adequate Intake ${ }^{(26-29)}$.

§Dietary reference intake: Estimated Average Requirement ${ }^{(26-29)}$.

$\|$ From Van Heerden and Parry ${ }^{(46)}$.

than the EAR or AI was allocated $100 \%$. The scores were added up, giving a total of 1900 for the Deficiency Score and 600 for the Excess Score. To simplify the interpretation, it was decided to combine the Deficiency Score and Excess Score into one score by subtracting the Excess Score from the Deficiency Score, now called the Adapted Thiele Score. This principle of being 'penalized' for non-preferable dietary intakes is used in most DQS ${ }^{(31-33)}$. The original HDI score was adapted for the present study by first using the more recent WHO prevention of CVD guidelines ${ }^{(34)}$ for the cut-off points and second by changing the scoring system from a dichotomous variable ( 1 or 0 ) to a continuous score in order to provide a more sensitive scoring range, instead of using very strict cut-offs.
An additional modification regarding $\mathrm{Na}$ intake was made, due to the fact that the QFFQ did not specifically evaluate the intake of discretionary salt. Charlton et al. ${ }^{(35)}$ showed that discretionary salt intake made up $45.5 \%$ of total $\mathrm{Na}$ intake in black South Africans. The Na intake of the population was therefore adjusted by adding $46 \%$ to the $\mathrm{Na}$ intake. Another modification was made regarding the cut-off point for fat, since the fat intake of this population was quite low with a mean of $24 \%$ of total energy. The cut-off for total fat intake in the Excess Score was lowered from $35 \%$ to $30 \%$, so that those taking a higher fat intake within the study population would be 'penalized'. The last adjustment that was made was to remove the contribution of alcohol to total energy intake. 
The median intake of alcohol was alarmingly high, particularly in the men, as has been previously described ${ }^{(36)}$. This was diluting the contribution of the macronutrients to energy, particularly in those with a very high alcohol intake.

\section{Statistical analysis}

Data were analysed using the statistical software package IBM SPSS Statistics 20. A $P$ value $\leq 0.05$ was regarded as statistically significant. Normally distributed variables are reported as mean and 95\% confidence interval, and non-normally distributed data as median and 25th-75th percentile. Mann-Whitney $U$ tests were used for comparisons between two groups. ANOVA, with post hoc comparisons, was used for comparison between three or more groups. Bland-Altman plots were constructed to assess the agreement between the two DQS.

\section{Results}

Table 2 provides details on the general characteristics of the total study population, as well as for the rural men and women and the urban men and women separately. The urban women had a significantly higher BMI, waist circumference, TAG, C-reactive protein and fasting glucose levels than their rural counterparts. Both systolic and diastolic blood pressures were significantly higher in the urban men and women, compared with the rural groups. The same was seen for plasminogen activator inhibitor-1 levels. The rural groups were significantly more active than their urban counterparts. In the rural groups the majority of men and women were uneducated, while in the urban groups, the majority had a primary school education. About $17 \%$ of the total group were newly diagnosed as HIV positive, with no significant differences between the rural and urban groups.

Table 3 provides the mean DQS scores and the mean intakes of the nutrients and foods that were used in the calculation of the DQS for the rural and urban groups. This table shows that the urban men and women had significantly higher dietary intakes than their rural counterparts for all nutrients and foods, except for carbohydrate as a percentage of energy. Table 3 also provides the percentage difference between the urban and rural groups' intakes, where urban intakes are expressed as a percentage increase or decrease compared with the rural intakes. Fat intake was over $40 \%$ and $\mathrm{Na}$ intake over $100 \%$ higher in the urban groups. Intakes of vitamin C, vitamin $\mathrm{B}_{12}$, vitamin $\mathrm{A}$ and riboflavin in the urban groups were more than double the intakes in the rural groups, with Ca intake in urban women being more than twice as high as that seen in rural women.

It is also evident that although nutrients such as total fat as a percentage of energy and cholesterol, as well as foods such as fruit and vegetables and pulses, nuts and seeds were significantly higher in the urban than the rural groups, they were still below the relevant guidelines. The median percentage of energy from total fat in the urban groups, although still below, was however approaching the CVD guideline of $30 \%$. When looking at Table 4 , it is clear that micronutrient intakes of this population are of concern, as can be seen from the large percentage of both the rural and urban groups that did not meet the EAR/AI. When comparing micronutrients expressed as a percentage of the EAR/AI, it is clear that the urban groups' median intakes were above $100 \%$ for twelve of the eighteen micronutrients ( $\mathrm{Fe}$, vitamin $\mathrm{B}_{12}, \mathrm{Cu}$, thiamin, vitamin $\mathrm{A}$, niacin, vitamin $\mathrm{B}_{6}$, folate, riboflavin, $\mathrm{Zn}, \mathrm{Mn}$ and $\mathrm{Mg}$ ), while it was not the case for the rural groups (four only). Despite the higher micronutrient intakes in the urban groups compared with the rural groups, micronutrients specifically linked to CVD prevention such as fibre, $\mathrm{Ca}, \mathrm{K}$ and vitamin $\mathrm{C}$ were far below the $\mathrm{EAR} / \mathrm{AI}$ in both the rural and urban groups.

Both DQS also indicated improved diet quality in the urban groups compared with the rural groups (Table 3). The HDI indicated a $7 \%$ and $5 \%$ increase in diet quality in the urban men and women respectively compared with their rural counterparts. When comparing the Deficiency Scores and Excess Scores which make up the Adapted Thiele Score, it is clear that the rural-urban increases of the Deficiency Score (17\% and 17\% for men and women respectively) were higher than the increases in the Excess Score $(0.4 \%$ and $2 \%)$. In order to determine the agreement between the two DQS, each participant's scores were expressed as a percentage of the total score. The scores as percentages of the total were then correlated with each other. The two scores correlated significantly with each other for both the rural $(r=0.6 ; P<0 \cdot 0001)$ and the urban $(r=0 \cdot 7 ; P<0 \cdot 0001)$ groups. In order to determine whether the differences between the scores were consistent across the total range of DQS values, Bland-Altman plots were constructed (Fig. 1). At a percentage of less than $70 \%$ of the total possible DQS, the HDI gave consistently higher scores than the Adapted Thiele Score, while at a percentage of greater than $70 \%$ the Adapted Thiele Score gave consistently higher scores. This explains the agreement between the two scores in the rural group, where the median DQS expressed as a percentage of the total was about $70 \%$ ( $72 \%$ for HDI in men and women; $72 \%$ and $73 \%$ for Adapted Thiele Score in men and women respectively), and the disagreement between the two scores in the urban groups with the higher DQS (where the median HDI was $77 \%$ and $76 \%$ for men and women respectively and the Adapted Thiele Score was $84 \%$ for both men and women).

\section{Discussion}

The present study is one of only a few to investigate the association between increased CVD risk during 
Table 2 Comparison of general characteristics of study participants according to sex and rural/urban grouping: apparently healthy volunteers from the South African Prospective Urban and Rural Epidemiological (PURE) study population ( $n$ 1710)

\begin{tabular}{|c|c|c|c|c|c|c|c|c|c|c|c|c|}
\hline & & & \multicolumn{4}{|c|}{ Men } & \multirow[b]{3}{*}{$P$} & \multicolumn{5}{|c|}{ Women } \\
\hline & \multicolumn{2}{|c|}{ Total $(n 1710)$} & \multicolumn{2}{|c|}{ Rural (n 314) } & \multicolumn{2}{|c|}{ Urban ( $n$ 328) } & & \multicolumn{2}{|c|}{ Rural ( $n$ 588) } & \multicolumn{2}{|c|}{ Urban ( $n$ 480) } & \multirow[b]{2}{*}{$P$} \\
\hline & $\begin{array}{l}\text { Median or } \\
\text { mean }\end{array}$ & $\begin{array}{c}\mathrm{P} 25-\mathrm{P} 75 \text { or } \\
95 \% \mathrm{Cl}\end{array}$ & $\begin{array}{l}\text { Median or } \\
\text { mean }\end{array}$ & $\begin{array}{c}\mathrm{P} 25-\mathrm{P} 75 \text { or } \\
95 \% \mathrm{Cl}\end{array}$ & $\begin{array}{l}\text { Median or } \\
\text { mean }\end{array}$ & $\begin{array}{c}\mathrm{P} 25-\mathrm{P} 75 \text { or } \\
95 \% \mathrm{Cl}\end{array}$ & & $\begin{array}{l}\text { Median or } \\
\text { mean }\end{array}$ & $\begin{array}{c}\mathrm{P} 25-\mathrm{P} 75 \text { or } \\
95 \% \mathrm{Cl}\end{array}$ & $\begin{array}{l}\text { Median or } \\
\text { mean }\end{array}$ & $\begin{array}{c}\mathrm{P} 25-\mathrm{P} 75 \text { or } \\
95 \% \mathrm{Cl}\end{array}$ & \\
\hline Age (years) & $48 \cdot 0$ & $41 \cdot 0-56 \cdot 0$ & $48 \cdot 0$ & $41 \cdot 0-56 \cdot 3$ & $49 \cdot 0$ & $42 \cdot 0-58 \cdot 0$ & 0.33 & $46 \cdot 0$ & $40 \cdot 0-54 \cdot 0$ & $48 \cdot 5$ & $42 \cdot 0-58 \cdot 8$ & $<0.0001$ \\
\hline BMI $\left(\mathrm{kg} / \mathrm{m}^{2}\right)$ & $22 \cdot 8$ & $19 \cdot 3-28 \cdot 4$ & $19 \cdot 7$ & $18 \cdot 1-22 \cdot 3$ & $20 \cdot 0$ & $18 \cdot 3-22 \cdot 8$ & 0.43 & $24 \cdot 6$ & $20 \cdot 7-30 \cdot 2$ & $27 \cdot 0$ & $22 \cdot 2-32 \cdot 5$ & $<0.0001$ \\
\hline WC $(\mathrm{cm})$ & $77 \cdot 0$ & $70 \cdot 2-87 \cdot 4$ & $74 \cdot 6$ & $70 \cdot 1-80 \cdot 5$ & $74 \cdot 4$ & $70 \cdot 0-81 \cdot 4$ & 0.85 & $78 \cdot 2$ & $69 \cdot 3-89 \cdot 1$ & $82 \cdot 1$ & $72 \cdot 7-92 \cdot 6$ & $<0.0001$ \\
\hline $\mathrm{TC}(\mathrm{mmol} / \mathrm{l})$ & $5 \cdot 03$ & $1 \cdot 33,1 \cdot 42$ & $4 \cdot 72$ & $1 \cdot 24,1 \cdot 45$ & 4.89 & $1 \cdot 20,1 \cdot 40$ & $0 \cdot 11$ & $5 \cdot 12$ & $1 \cdot 30,1 \cdot 45$ & $5 \cdot 22$ & $1 \cdot 33,1 \cdot 51$ & 0.23 \\
\hline $\mathrm{HDL}-\mathrm{C}(\mathrm{mmol} / \mathrm{l})$ & $1 \cdot 42$ & $1.06-1.89$ & $1 \cdot 41$ & $1.02-1.95$ & 1.52 & $1 \cdot 13-2 \cdot 05$ & 0.06 & $1 \cdot 41$ & $1.09-1.85$ & $1 \cdot 36$ & $1 \cdot 01-1 \cdot 78$ & 0.21 \\
\hline LDL-C (mmol/l/ & 3.25 & $1 \cdot 18,1 \cdot 26$ & $2 \cdot 96$ & $1 \cdot 10,1 \cdot 29$ & 3.02 & $1 \cdot 09,1 \cdot 28$ & 0.56 & $3 \cdot 36$ & $1 \cdot 17,1 \cdot 31$ & $3 \cdot 46$ & $1 \cdot 13,1 \cdot 28$ & $0 \cdot 19$ \\
\hline $\mathrm{TAG}(\mathrm{mmol} / \mathrm{l})$ & 1.09 & $0.82-1.54$ & 0.96 & $0.75-1.34$ & 1.00 & $0.79-1.46$ & 0.21 & $1 \cdot 10$ & $0.82-1.49$ & $1 \cdot 21$ & $0.89-1.79$ & $<0.001$ \\
\hline SBP $(\mathrm{mmHg})$ & 133 & 132,134 & 132 & 129,135 & 138 & 135,140 & $<0.01$ & 127 & 125,129 & 137 & 134,139 & $<0.0001$ \\
\hline DBP $(\mathrm{mmHg})$ & $87 \cdot 4$ & $86 \cdot 7,88 \cdot 0$ & 84.9 & $83 \cdot 2,86 \cdot 6$ & $88 \cdot 0$ & $86 \cdot 5,89 \cdot 6$ & $<0.01$ & $86 \cdot 6$ & $85 \cdot 4,87 \cdot 7$ & 89.5 & $88 \cdot 3,90 \cdot 8$ & $<0.001$ \\
\hline CRP $(\mathrm{mg} / \mathrm{l})$ & $3 \cdot 20$ & $0.93-9.20$ & $2 \cdot 70$ & $0.63-8.04$ & $2 \cdot 29$ & $0.83-7.53$ & 0.85 & 3.50 & $1.03-9.20$ & 3.87 & $1 \cdot 43-11 \cdot 40$ & 0.04 \\
\hline $\mathrm{FG}(\mathrm{mmol} / \mathrm{l})$ & $4 \cdot 80$ & $4 \cdot 30-5 \cdot 30$ & $4 \cdot 70$ & $4 \cdot 40-5 \cdot 10$ & $4 \cdot 80$ & $4 \cdot 20-5 \cdot 40$ & 0.38 & $4 \cdot 80$ & $4 \cdot 40-5 \cdot 20$ & 4.95 & $4 \cdot 30-5 \cdot 50$ & 0.01 \\
\hline PAl-1 (U/ml) & $4 \cdot 27$ & $1.24-7.99$ & 1.95 & $0.00-4.72$ & $2 \cdot 85$ & $0 \cdot 18-6 \cdot 74$ & $<0.01$ & 4.59 & $1 \cdot 84-7 \cdot 76$ & $6 \cdot 28$ & $3 \cdot 25-10 \cdot 68$ & $<0.0001$ \\
\hline \multirow[t]{2}{*}{ PAI $(n 1645)$} & 3.0 & $2 \cdot 5-3 \cdot 2$ & 3.0 & $2 \cdot 6-3 \cdot 4$ & $2 \cdot 7$ & $2 \cdot 4-3 \cdot 0$ & $<0.0001$ & $3 \cdot 1$ & $2 \cdot 7-3 \cdot 4$ & $2 \cdot 7$ & $2 \cdot 5-3 \cdot 0$ & $<0.0001$ \\
\hline & $n$ & $\%$ & $n$ & $\%$ & $n$ & $\%$ & $P$ & $n$ & $\%$ & $n$ & $\%$ & $P$ \\
\hline Education & \multicolumn{2}{|c|}{$(n$ 1608) } & \multicolumn{2}{|c|}{ (n 294) } & \multicolumn{2}{|c|}{ (n 311) } & & \multicolumn{2}{|c|}{ (n 553) } & \multicolumn{2}{|c|}{$(n$ 450) } & \\
\hline None & 592 & $36 \cdot 8$ & 155 & $52 \cdot 7$ & 79 & $25 \cdot 4$ & $<0.00001$ & 265 & $47 \cdot 9$ & 93 & $20 \cdot 7$ & $<0.00001$ \\
\hline Primary school & 668 & 41.5 & 92 & $31 \cdot 3$ & 150 & $48 \cdot 2$ & $<0.00001$ & 169 & $30 \cdot 6$ & 257 & $57 \cdot 1$ & $<0.00001$ \\
\hline Secondary school & 336 & $20 \cdot 9$ & 43 & $14 \cdot 6$ & 78 & $25 \cdot 1$ & $<0.001$ & 118 & $21 \cdot 3$ & 97 & $21 \cdot 6$ & 0.91 \\
\hline University/college & 12 & 0.8 & 4 & $1 \cdot 4$ & 4 & 1.3 & 0.92 & 1 & 0.2 & 3 & 0.7 & 0.23 \\
\hline HIV status (newly & \multicolumn{2}{|c|}{$(n$ 1703) } & \multicolumn{2}{|c|}{$(n 314)$} & \multicolumn{2}{|c|}{$(n$ 327) } & & \multicolumn{2}{|c|}{$(n 586)$} & \multicolumn{2}{|c|}{$(n 476)$} & \\
\hline Positive & 290 & $17 \cdot 0$ & 56 & $17 \cdot 8$ & 49 & $15 \cdot 0$ & 0.34 & 101 & $17 \cdot 2$ & 84 & $17 \cdot 7$ & 0.83 \\
\hline Negative & 1413 & 83.0 & 258 & $82 \cdot 2$ & 278 & $85 \cdot 0$ & 0.34 & 485 & $82 \cdot 8$ & 392 & $82 \cdot 4$ & 0.86 \\
\hline Smoking status & \multicolumn{2}{|c|}{$(n$ 1702) } & \multicolumn{2}{|c|}{$(n$ 313) } & \multicolumn{2}{|c|}{$(n 325)$} & & \multicolumn{2}{|c|}{$(n$ 587) } & \multicolumn{2}{|c|}{$(n$ 477) } & \\
\hline Former & 69 & $4 \cdot 1$ & 21 & 6.7 & 24 & $7 \cdot 3$ & 0.73 & 15 & $2 \cdot 6$ & 9 & 1.9 & 0.44 \\
\hline Current & 897 & $52 \cdot 7$ & 173 & $55 \cdot 3$ & 209 & $64 \cdot 3$ & $<0.01$ & 289 & $49 \cdot 2$ & 226 & $47 \cdot 4$ & 0.56 \\
\hline Never & 736 & $43 \cdot 2$ & 119 & $38 \cdot 0$ & 325 & $28 \cdot 3$ & $<0.001$ & 283 & $48 \cdot 2$ & 242 & $50 \cdot 7$ & 0.42 \\
\hline
\end{tabular}

P25, 25th percentile; P75, 75th percentile; WC, waist circumference; TC, total cholesterol; HDL-C, HDL-cholesterol; LDL-C, LDL-cholesterol; SBP, systolic blood pressure; DBP, diastolic blood pressure; CRP, C-reactive cal activity index.

Normally distributed data reported as mean and $95 \%$ confidence interval; non-parametric data reported as median and 25 th-75th percentile. 
Table 3 Comparison of nutrient and food group intakes, and diet quality scores, according to sex and rural/urban grouping: apparently healthy volunteers from the South African Prospective Urban and Rural Epidemiological (PURE) study population ( $n$ 1710)

\begin{tabular}{|c|c|c|c|c|c|c|c|c|c|c|}
\hline & \multicolumn{5}{|c|}{ Men } & \multicolumn{5}{|c|}{ Women } \\
\hline & \multicolumn{2}{|c|}{ Rural ( $n$ 314) } & \multicolumn{2}{|c|}{ Urban ( $n$ 328) } & \multirow{2}{*}{$\begin{array}{c}\% \text { difference between } \\
\mathrm{R} \text { and } \mathrm{U}^{\star}\end{array}$} & \multicolumn{2}{|c|}{ Rural ( $n$ 588) } & \multicolumn{2}{|c|}{ Urban ( $n$ 480) } & \multirow{2}{*}{$\begin{array}{l}\% \text { difference between } \\
\qquad \mathrm{R} \text { and } \mathrm{U}^{*}\end{array}$} \\
\hline & Median & P25-P75 & Median & P25-P75 & & Median & P25-P75 & Median & P25-P75 & \\
\hline \multicolumn{11}{|l|}{ Nutrients } \\
\hline Energy (kJ) & $6029+$ & $4765-7757$ & $8603+$ & $6516-11288$ & 42 & $5677 \ddagger$ & $4446-7169$ & $7664 \ddagger$ & $5366-10401$ & 35 \\
\hline Protein (\%TE) & $11 \cdot 6+$ & $10 \cdot 4-12 \cdot 9$ & $13 \cdot 2 t$ & $12 \cdot 0-14 \cdot 2$ & 13 & $11 \cdot 1 \ddagger$ & $10 \cdot 0-12 \cdot 3$ & $12 \cdot 9 \ddagger$ & $11 \cdot 8-14 \cdot 1$ & 16 \\
\hline Carbohydrate (\%TE) & $69 \cdot 9+$ & $64 \cdot 9-73 \cdot 9$ & $59 \cdot 9+$ & $56 \cdot 0-64 \cdot 2$ & $\downarrow 14$ & $68 \cdot 9 \ddagger$ & $63 \cdot 5-73 \cdot 2$ & $58 \cdot 0 \ddagger$ & $53 \cdot 6-62 \cdot 9$ & $\downarrow 16$ \\
\hline Total fat (\%TE) & $18 \cdot 7 \dagger$ & $15 \cdot 0-23 \cdot 3$ & $26 \cdot 7 \dagger$ & $22 \cdot 8-29 \cdot 9$ & 43 & $19 \cdot 9 \ddagger$ & $15 \cdot 9-24 \cdot 6$ & $29 \cdot 1 \ddagger$ & $24 \cdot 4-33 \cdot 0$ & 46 \\
\hline SFA (\%TE) & $3.94 t$ & $2 \cdot 59-5 \cdot 25$ & $6 \cdot 47 t$ & $5 \cdot 34-7 \cdot 79$ & 64 & $4 \cdot 14 \ddagger$ & $2 \cdot 90-5 \cdot 77$ & $7 \cdot 19 \ddagger$ & $5 \cdot 92-8 \cdot 77$ & 74 \\
\hline PUFA (\%TE) & $6 \cdot 10+$ & $4 \cdot 24-7 \cdot 86$ & $7 \cdot 49+$ & $6 \cdot 14-9 \cdot 19$ & 23 & $6 \cdot 61 \ddagger$ & $4 \cdot 86-8 \cdot 52$ & $8 \cdot 17 \ddagger$ & $6 \cdot 56-9 \cdot 71$ & 24 \\
\hline Cholesterol (mg) & $106+$ & $56-153$ & $234 t$ & $149-331$ & 121 & $95 \ddagger$ & $49-151$ & $205 \ddagger$ & $131-310$ & 115 \\
\hline Added sugar (\%TE) & $6 \cdot 13+$ & $3 \cdot 51-8 \cdot 86$ & $6 \cdot 94 t$ & $4 \cdot 63-9 \cdot 88$ & 13 & $6 \cdot 76 \ddagger$ & $3 \cdot 79-10 \cdot 40$ & $8 \cdot 38 \ddagger$ & $6 \cdot 08-11 \cdot 10$ & 24 \\
\hline Alcohol $(\mathrm{g})$ & $2 \cdot 04 t$ & $0 \cdot 00-28 \cdot 60$ & $11 \cdot 6+$ & $0.00-26 \cdot 70$ & 469 & $0.00 \ddagger$ & $0.00-0.00$ & $0.00 \ddagger$ & $0 \cdot 00-10 \cdot 20$ & 0 \\
\hline Dietary fibre (g) & $18 \cdot 1 \dagger$ & $12 \cdot 6-24 \cdot 2$ & $24 \cdot 0 t$ & $16 \cdot 5-33 \cdot 2$ & 33 & $16 \cdot 5 \ddagger$ & $12 \cdot 5-21 \cdot 3$ & $20 \cdot 4 \ddagger$ & $13 \cdot 3-28 \cdot 5$ & 24 \\
\hline $\mathrm{Ca}(\mathrm{mg})$ & $213 t$ & $139-309$ & $369+$ & $277-535$ & 73 & $186 \ddagger$ & $114-267$ & $368 \ddagger$ & $263-586$ & 98 \\
\hline $\mathrm{Mg}(\mathrm{mg})$ & $277 \dagger$ & $194-421$ & $379+$ & $277-519$ & 37 & $225 \ddagger$ & $172-299$ & $296 \ddagger$ & $203-402$ & 32 \\
\hline $\mathrm{Fe}(\mathrm{mg})$ & $11 \cdot 9+$ & $8 \cdot 7-15 \cdot 2$ & $15 \cdot 1+$ & $10 \cdot 8-20 \cdot 9$ & 27 & $10 \cdot 6 \ddagger$ & $8 \cdot 1-13 \cdot 4$ & $12 \cdot 3 \ddagger$ & $8 \cdot 3-17 \cdot 5$ & 16 \\
\hline $\mathrm{Zn}(\mathrm{mg})$ & $8 \cdot 27 \dagger$ & $6 \cdot 24-10 \cdot 80$ & $11 \cdot 8 t$ & $8 \cdot 58-16 \cdot 80$ & 43 & $7 \cdot 34 \ddagger$ & $5 \cdot 62-9 \cdot 34$ & $9 \cdot 62 \ddagger$ & $6 \cdot 74-14 \cdot 00$ & 31 \\
\hline $\mathrm{Mn}(\mathrm{mg})$ & $1554 t$ & $834-3051$ & $2488+$ & 1765-3482 & 60 & $1158 \ddagger$ & 667-1829 & $1998 \ddagger$ & 1359-2913 & 73 \\
\hline $\mathrm{K}(\mathrm{mg})$ & $1309+$ & $956-1714$ & $1988+$ & $1449-2741$ & 52 & $1160 \ddagger$ & $905-1499$ & $1828 \ddagger$ & $1193-2488$ & 58 \\
\hline $\mathrm{Na}(\mathrm{mg})$ & $726+$ & $361-1063$ & $1673+$ & $1179-2370$ & 130 & $674 \ddagger$ & $406-1039$ & $1808 \ddagger$ & $1229-2684$ & 168 \\
\hline $\mathrm{Cu}(\mu \mathrm{g})$ & $102 \dagger$ & $76-139$ & $139 t$ & $103-186$ & 36 & $95 \ddagger$ & $70-121$ & $126 \ddagger$ & $85-173$ & 33 \\
\hline Vitamin A $(\mu \mathrm{g})$ & $409+$ & $257-648$ & $809+$ & $523-1439$ & 98 & $452 \ddagger$ & $289-693$ & $828 \ddagger$ & $408-1398$ & 83 \\
\hline Thiamin (mg) & $1 \cdot 54 \dagger$ & $1 \cdot 12-2 \cdot 02$ & $1 \cdot 78 t$ & $1 \cdot 31-2 \cdot 68$ & 16 & $1 \cdot 36 \ddagger$ & $1 \cdot 04-1 \cdot 74$ & $1 \cdot 41 \ddagger$ & $0 \cdot 98-2 \cdot 10$ & 4 \\
\hline Riboflavin (mg) & $0.8 \dagger$ & $0 \cdot 6-1 \cdot 4$ & $1 \cdot 5 t$ & $1 \cdot 1-2 \cdot 0$ & 88 & $0.7 \ddagger$ & $0.5-1.0$ & $1 \cdot 3 \ddagger$ & $0.9-1.9$ & 86 \\
\hline Niacin (mg) & $11 \cdot 3+$ & $8 \cdot 6-16 \cdot 3$ & $17 \cdot 2+$ & $13 \cdot 0-23 \cdot 2$ & 52 & $9 \cdot 9 \ddagger$ & $7 \cdot 6-12 \cdot 6$ & $14 \cdot 3 \ddagger$ & $9 \cdot 9-20 \cdot 4$ & 44 \\
\hline Vitamin $\mathrm{B}_{6}(\mathrm{mg})$ & $1 \cdot 21 t$ & $0 \cdot 84-1 \cdot 61$ & $1 \cdot 67 t$ & $1 \cdot 14-2 \cdot 56$ & 38 & $1 \cdot 10 \ddagger$ & $0.84-1 \cdot 43$ & $1 \cdot 40 \ddagger$ & $0.89-2 \cdot 06$ & 27 \\
\hline Folate $(\mu \mathrm{g})$ & $359+$ & $228-460$ & $438+$ & $304-625$ & 57 & $317 \ddagger$ & $224-417$ & $339 \ddagger$ & $235-490$ & 7 \\
\hline Vitamin $B_{12}(\mu \mathrm{g})$ & $1 \cdot 52 \dagger$ & $0 \cdot 82-2 \cdot 90$ & $4 \cdot 47 \dagger$ & $2 \cdot 45-7 \cdot 47$ & 194 & $1 \cdot 54 \ddagger$ & $0 \cdot 68-2 \cdot 93$ & $4 \cdot 00 \ddagger$ & $2 \cdot 08-6 \cdot 74$ & 159 \\
\hline Pantothenic acid (mg) & $2 \cdot 70 t$ & $1 \cdot 92-3 \cdot 63$ & $4 \cdot 65 t$ & $3 \cdot 17-6 \cdot 22$ & 72 & $2 \cdot 47 \ddagger$ & $1 \cdot 87-3 \cdot 32$ & $4 \cdot 20 \ddagger$ & $2 \cdot 77-5 \cdot 72$ & 70 \\
\hline Vitamin C (mg) & $11 \cdot 2 \dagger$ & $6 \cdot 1-15 \cdot 5$ & $30 \cdot 7 \dagger$ & $17 \cdot 8-55 \cdot 4$ & 174 & $11 \cdot 9 \ddagger$ & $7 \cdot 3-17 \cdot 6$ & $32 \cdot 1 \ddagger$ & $17 \cdot 0-53 \cdot 9$ & 170 \\
\hline \multicolumn{11}{|l|}{ Foods } \\
\hline Fruit \& vegetables $(\mathrm{g})$ & $58 \cdot 9+$ & $33 \cdot 8-83 \cdot 0$ & $129+$ & $81 \cdot 4-216$ & 119 & $69 \cdot 3 \ddagger$ & $43 \cdot 6-100$ & $148 \ddagger$ & $84 \cdot 6-231$ & 114 \\
\hline Pulses, nuts, seeds (g) & $0.0+$ & $0 \cdot 0-10 \cdot 0$ & $9 \cdot 6+$ & $0 \cdot 0-28 \cdot 6$ & 860 & $0.0 \ddagger$ & $0 \cdot 0-11 \cdot 6$ & $11 \cdot 0 \ddagger$ & $0 \cdot 0-29 \cdot 4$ & 900 \\
\hline \multicolumn{11}{|l|}{ Diet quality scores } \\
\hline Adapted Thiele Score & $1364+$ & $1172-1504$ & $1594 \dagger$ & $1448-1662$ & \multirow{2}{*}{\multicolumn{3}{|c|}{72}} & $1592 \ddagger$ & $1388-1684$ & 15 \\
\hline$\%$ of total score & \multicolumn{2}{|c|}{72} & \multicolumn{2}{|c|}{84} & & & & \multicolumn{2}{|c|}{84} & \\
\hline Deficiency Score & $1409+$ & $1196-1549$ & $1649+$ & $1520-1753$ & 17 & $1413 \ddagger$ & $1215-1547$ & $1657 \ddagger$ & $1444-1765$ & 17 \\
\hline New Excess Score & 583 & $500-600$ & 595 & $541-600$ & $0 \cdot 4$ & 553 & $495-591$ & 555 & $500-588$ & 2 \\
\hline \multirow{2}{*}{$\begin{array}{l}\text { Healthy Diet Indicator } \\
\% \text { of total score }\end{array}$} & $6 \cdot 46 t$ & $5 \cdot 91-6 \cdot 89$ & $6.94 t$ & $6 \cdot 36-7 \cdot 44$ & \multirow{2}{*}{\multicolumn{3}{|c|}{$6 \cdot 48 \neq 72^{6 \cdot 03-6 \cdot 95}$}} & $6 \cdot 82 \ddagger$ & $6 \cdot 11-7 \cdot 36$ & 5 \\
\hline & \multicolumn{2}{|c|}{72} & \multicolumn{2}{|c|}{77} & & & & \multicolumn{2}{|c|}{76} & \\
\hline
\end{tabular}

P25, 25th percentile; P75, 75th percentile; R, rural; U, urban; \%TE, percentage of total energy

Data reported as median and P25-P75.

*\% indicates increase except for $\downarrow$ for carbohydrate, which indicates a decrease.

tSignificant difference between rural and urban men: $P<0.01$.

$\ddagger$ Significant difference between rural and urban women: $P<0.01$. 
Table 4 Nutrient intake expressed as a percentage of the EAR/Al for micronutrients and percentage who did not meet the EAR/Al: apparently healthy volunteers from the South African Prospective Urban and Rural Epidemiological (PURE) study population ( $n$ 1710)

\begin{tabular}{|c|c|c|c|c|c|c|c|c|c|c|c|c|c|c|c|c|c|c|}
\hline & \multicolumn{8}{|c|}{$\%$ of $\mathrm{EAR} / \mathrm{Al}$} & \multicolumn{10}{|c|}{ Did not meet EAR/Al } \\
\hline & \multicolumn{4}{|c|}{ Rural } & \multicolumn{4}{|c|}{ Urban } & \multicolumn{6}{|c|}{ Rural } & \multicolumn{4}{|c|}{ Urban } \\
\hline & \multicolumn{2}{|c|}{$\begin{array}{c}\text { Men } \\
(n 314)\end{array}$} & \multicolumn{2}{|c|}{$\begin{array}{l}\text { Women } \\
(n \text { 588) }\end{array}$} & \multicolumn{2}{|c|}{$\begin{array}{c}\text { Men } \\
(n \text { 328) }\end{array}$} & \multicolumn{2}{|c|}{$\begin{array}{l}\text { Women } \\
(n \text { 480) }\end{array}$} & \multicolumn{2}{|c|}{$\begin{array}{c}\text { Total } \\
(n \text { 1710 })\end{array}$} & \multicolumn{2}{|c|}{$\begin{array}{c}\text { Men } \\
(n \text { 314) }\end{array}$} & \multicolumn{2}{|c|}{$\begin{array}{l}\text { Women } \\
\text { (n 588) }\end{array}$} & \multicolumn{2}{|c|}{$\begin{array}{c}\text { Men } \\
(n \text { 328) }\end{array}$} & \multicolumn{2}{|c|}{$\begin{array}{l}\text { Women } \\
(n \text { 480) }\end{array}$} \\
\hline & Median & P25-P75 & Median & P25-P75 & Median & P25-P75 & Median & P25-P75 & $\%$ & $n$ & $\%$ & $n$ & $\%$ & $n$ & $\%$ & $n$ & $\%$ & $n$ \\
\hline Dietary fibre $(\mathrm{g})$ & $52 \cdot 7^{\star}$ & $36 \cdot 4-71 \cdot 4$ & $70 \cdot 0+$ & $52 \cdot 9-89 \cdot 8$ & $71 \cdot 0^{*}$ & $46 \cdot 7-100$ & $85 \cdot 7 \dagger$ & $56 \cdot 2-124$ & $77 \cdot 6$ & 1327 & $95 \cdot 2$ & 299 & $84 \cdot 5$ & 497 & $75 \cdot 0$ & 246 & $59 \cdot 4$ & 285 \\
\hline $\mathrm{Ca}(\mathrm{n}$ & $19 \cdot 4^{*}$ & $12 \cdot 4-28 \cdot 9$ & $15 \cdot 5 t$ & $9 \cdot 5-22 \cdot 2$ & $35 \cdot 3^{*}$ & $25 \cdot 5-49 \cdot 0$ & $30 \cdot 6+$ & $21 \cdot 9-48 \cdot 8$ & $99 \cdot 0$ & 1692 & $99 \cdot 0$ & 311 & $100 \cdot 0$ & 588 & $96 \cdot 3$ & 316 & $99 \cdot 4$ & 477 \\
\hline $\mathrm{Mg}(\mathrm{mg})$ & $79 \cdot 2^{\star}$ & $55 \cdot 5-120$ & $70 \cdot 4 t$ & $53 \cdot 8-93 \cdot 6$ & $108^{*}$ & $79 \cdot 0-148$ & $92+$ & $63 \cdot 5-126$ & $62 \cdot 7$ & 1072 & $66 \cdot 6$ & 209 & $80 \cdot 1$ & 471 & $40 \cdot 6$ & 133 & $54 \cdot 0$ & 259 \\
\hline $\mathrm{Fe}(\mathrm{mg})$ & $198^{\star}$ & $144-254$ & $154 \dagger$ & 109-200 & $252^{*}$ & $180-348$ & $185+$ & $125-278$ & $14 \cdot 7$ & 251 & $13 \cdot 7$ & 43 & $18 \cdot 0$ & 106 & $7 \cdot 0$ & 23 & $16 \cdot 5$ & \\
\hline Zn (mg) & $88 \cdot 0^{*}$ & $66 \cdot 4-114$ & $108 \dagger$ & $82 \cdot 7-137$ & 126 & $91 \cdot 3-178$ & $141 t$ & 97.9-206 & $39 \cdot 4$ & 674 & $60 \cdot 8$ & 191 & $42 \cdot 9$ & 252 & $31 \cdot 4$ & 103 & $26 \cdot 7$ & 128 \\
\hline $\mathrm{Mn}(\mathrm{mg})$ & $67 \cdot 6^{*}$ & $36 \cdot 2-133$ & $64 \cdot 3+$ & $37 \cdot 0-102$ & $108^{*}$ & $76 \cdot 7-151$ & $111 \dagger$ & $75 \cdot 4-162$ & $58 \cdot 6$ & 1002 & $67 \cdot 2$ & 211 & $74 \cdot 3$ & 437 & $46 \cdot 0$ & 151 & $42 \cdot 3$ & 20 \\
\hline $\mathrm{K}(\mathrm{mg})$ & $27 \cdot 9^{*}$ & $20 \cdot 3-36 \cdot 5$ & $24 \cdot 7 \dagger$ & $19 \cdot 2-31 \cdot 9$ & $42 \cdot 3^{*}$ & $30 \cdot 8-58 \cdot 3$ & $38 \cdot 9+$ & $25 \cdot 4-52 \cdot 9$ & $99 \cdot 0$ & 1693 & $99 \cdot 7$ & 313 & $99 \cdot 7$ & 586 & $97 \cdot 3$ & 319 & $99 \cdot 0$ & 47 \\
\hline $\mathrm{Na}(\mathrm{mg})$ & $30 \cdot 9^{*}$ & $18 \cdot 1-47 \cdot 6$ & $29 \cdot 3 t$ & $17 \cdot 0-44 \cdot 9$ & $73 \cdot 2^{*}$ & $53 \cdot 5-107$ & $76 \cdot 2 t$ & $51 \cdot 3-112$ & $84 \cdot 6$ & 1446 & $97 \cdot 1$ & 305 & $98 \cdot 0$ & 576 & $71 \cdot 0$ & 233 & $69 \cdot 2$ & 332 \\
\hline $\mathrm{Cu}(\mu \mathrm{g})$ & $146^{*}$ & 108-199 & $135 t$ & $99 \cdot 4-173$ & $199^{*}$ & $147-265$ & $181+$ & $122-247$ & $18 \cdot 9$ & 323 & $19 \cdot 4$ & 61 & $25 \cdot 2$ & 148 & $11 \cdot 0$ & 36 & $16 \cdot 3$ & \\
\hline Vitamin $A(\mu \mathrm{g})$ & $81 \cdot 8^{*}$ & $51 \cdot 5-130$ & $72 \cdot 3+$ & $46 \cdot 2-111$ & $162^{*}$ & $105-288$ & $133+$ & $65 \cdot 4-225$ & $49 \cdot 7$ & 849 & $62 \cdot 4$ & 196 & $68 \cdot 2$ & 401 & $23 \cdot 5$ & 77 & $36 \cdot 5$ & 175 \\
\hline Thiamin (mg) & $154^{*}$ & $112-202$ & $151 t$ & 115-194 & $178^{*}$ & $131-268$ & $157 \dagger$ & 109-234 & $17 \cdot 5$ & 299 & $20 \cdot 1$ & 63 & $16 \cdot 0$ & 94 & $14 \cdot 0$ & 46 & $20 \cdot 0$ & \\
\hline Riboflavin (mg) & $75 \cdot 4^{*}$ & $56 \cdot 0-122$ & $77 \cdot 9+$ & $57 \cdot 0-108$ & $132^{*}$ & $65 \cdot 9-181$ & $145 t$ & $96 \cdot 0-206$ & $50 \cdot 2$ & 858 & $68 \cdot 5$ & 215 & $71 \cdot 1$ & 418 & $26 \cdot 8$ & 88 & $39 \cdot 9$ & 137 \\
\hline Niacin (mg) & $94 \cdot 5^{\star}$ & $71 \cdot 6-136$ & $90 \cdot 0 t$ & $68 \cdot 7-114$ & $143^{*}$ & 108-194 & $130 t$ & $89 \cdot 0-185$ & $44 \cdot 2$ & 755 & $55 \cdot 1$ & 173 & $61 \cdot 6$ & 362 & $19 \cdot 5$ & 64 & $32 \cdot 5$ & 15 \\
\hline Vitamin $B_{6}(\mathrm{mg})$ & $98 \cdot 1^{*}$ & $69-128$ & $95 \cdot 8 \dagger$ & $69 \cdot 9-122$ & $137^{*}$ & $87 \cdot 6-211$ & $117 \dagger$ & $75 \cdot 4-179$ & $45 \cdot 5$ & 778 & $50 \cdot 3$ & 158 & $54 \cdot 9$ & 323 & $31 \cdot 1$ & 102 & $40 \cdot 6$ & 19 \\
\hline Folate $(\mu \mathrm{g})$ & $112^{*}$ & $71 \cdot 3-144$ & $98 \cdot 9+$ & $69 \cdot 9-130$ & $137^{*}$ & $95 \cdot 1-195$ & $106 t$ & $73 \cdot 3-153$ & $43 \cdot 2$ & 738 & $42 \cdot 4$ & 133 & $51 \cdot 5$ & 303 & $27 \cdot 1$ & 89 & $44 \cdot 4$ & 21 \\
\hline Vitamin $B_{12}(\mu \mathrm{g})$ & $76 \cdot 1^{*}$ & $41 \cdot 1-145$ & $77 \cdot 2 \dagger$ & $33 \cdot 8-146$ & $223^{*}$ & 123-374 & $200 t$ & 104-337 & $42 \cdot 5$ & 727 & $61 \cdot 2$ & 192 & $61 \cdot 2$ & 360 & $18 \cdot 9$ & 62 & $23 \cdot 5$ & 113 \\
\hline Pantothenic acid (mg) & $54 \cdot 1^{*}$ & $38 \cdot 5-72 \cdot 6$ & $49 \cdot 4 \dagger$ & $37 \cdot 4-66 \cdot 3$ & $93 \cdot 0^{*}$ & $63 \cdot 4-125$ & $83 \cdot 9+$ & $55 \cdot 4-114$ & $77 \cdot 5$ & 1326 & $89 \cdot 5$ & 281 & $93 \cdot 7$ & 551 & $56 \cdot 7$ & 186 & $64 \cdot 2$ & \\
\hline Vitamin C (mg) & $14 \cdot 9^{*}$ & $8 \cdot 1-20 \cdot 7$ & $19 \cdot 8 t$ & $12 \cdot 1-29 \cdot 3$ & $41 \cdot 0^{*}$ & $23 \cdot 7-73 \cdot 9$ & $53 \cdot 0 t$ & $28 \cdot 3-89 \cdot 8$ & $91 \cdot 9$ & 1572 & $99 \cdot 7$ & 313 & $98 \cdot 1$ & 577 & $89 \cdot 0$ & 292 & $81 \cdot 0$ & 389 \\
\hline
\end{tabular}

EAR, Estimated Average Requirement; Al, Adequate Intake; P25, 25th percentile; P75, 75th percentile.

(26-29).

retween rural and urban men: $P<0.00001$

tSignificant difference between rural and urban women: $P<0 \cdot 01$ 

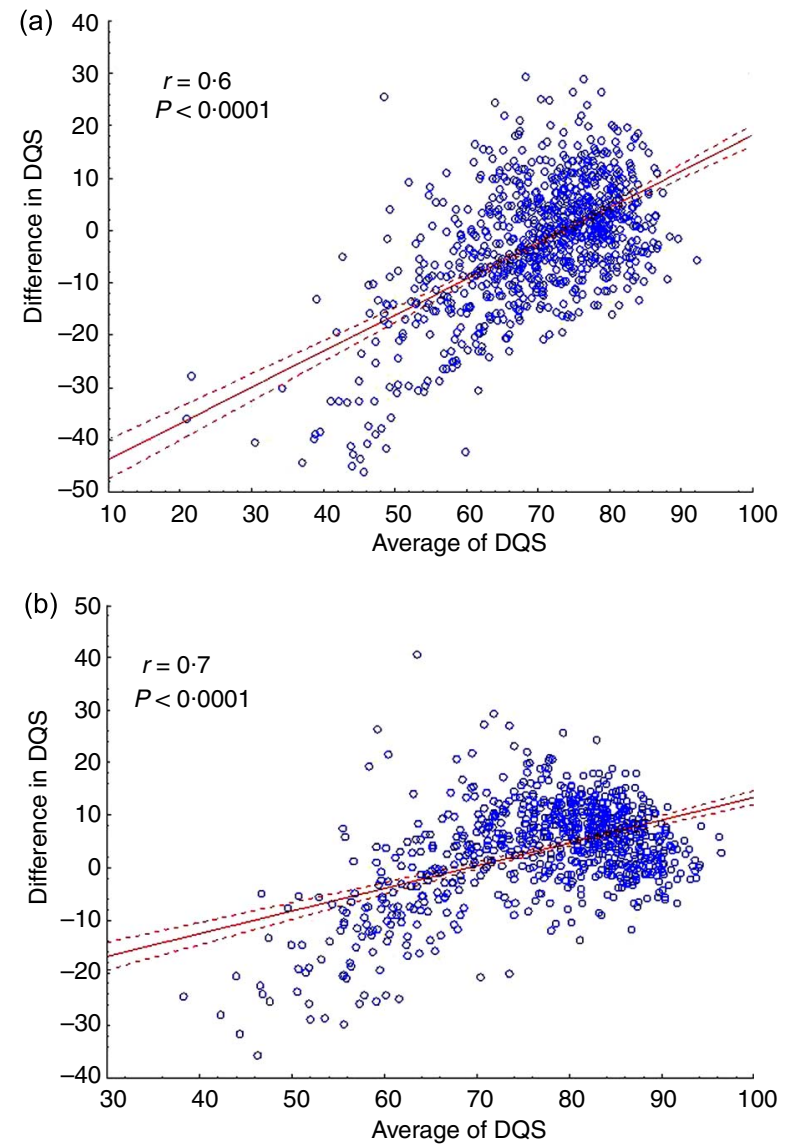

Fig. 1 (colour online) Bland-Altman plots showing the agreement between two predefined diet quality scores (DQS; the Healthy Diet Indicator ${ }^{(13)}$ and the Adapted Thiele Score $\left.{ }^{(12)}\right)$ in apparently healthy volunteers from the South African Prospective Urban and Rural Epidemiological (PURE) study population ( $n$ 1710): (a) rural group and (b) urban group

urbanization in a developing country and dietary intake by not only looking at individual nutrients, but also investigating dietary patterns by means of predefined DQS. It should be kept in mind that DQS have primarily been developed for Western countries and that their relevance for non-Western populations has not yet been confirmed $^{(37)}$. As can be seen from the increased levels of known CVD risk factors in our (black South African) study population, it is clear that the urban participants, especially urban women, were at an increased risk of CVD compared with their rural counterparts. Urban men smoked more than rural men, while there was no difference in HIV status between the groups. The rural group as a whole was furthermore less educated than the urban group, and significantly more active. The urban group with the higher risk for CVD therefore smoked more, was less active and with a higher education than the rural group with the lower CVD risk. Increasing CVD risk in populations undergoing urbanization has been described previously and changing dietary intake is accepted as one of the contributing factors ${ }^{(3,4)}$. For example, irregular fruit and vegetable intake has been identified as one of the nine risk factors that accounted for $\approx 97 \cdot 4 \%$ of observed acute myocardial infarctions in African populations ${ }^{(4)}$. Additionally, low dairy consumption, and high fat and red meat consumption, has been observed in an urbanizing South African population, who also presented with an increased risk for $\mathrm{CVD}^{(3,38)}$.

It has been understood that the traditional African rural diet is healthier and protective against CVD in that it is higher in fibre and fruit and vegetables and lower in animal products ${ }^{(5)}$. However, as can be seen from Table 3, in our population, the urban groups (both men and women) had significantly higher intakes of all macro- and micronutrients, except for carbohydrate as a percentage of energy, which was significantly lower in the urban groups. These levels of intakes were markedly higher when looking at the percentage difference in intake between the rural and urban groups. Of particular interest is total fat as a percentage of energy was $40 \%$ higher in the urban compared with the rural groups. Although the median intake in the urban groups was still below the CVD guideline of $30 \%$, it was, however, only just below, suggesting that at least $50 \%$ of the population was consuming fat at a level of (and higher than) the guideline. SFA, PUFA and cholesterol intakes were, on the other hand, well within the recommended ranges in both groups. This relatively low fat intake is similar to what has been seen in previous studies (THUSA) in this population ${ }^{(38)}$.

Despite the increased micronutrient intakes in the urban groups, intakes for some of the micronutrients were disconcertingly low when compared with the EAR/ AI. More than $80 \%$ of the population (in both urban and rural groups) for example did not reach the EAR/AI for dietary fibre, $\mathrm{Ca}$, vitamin $\mathrm{C}$ and $\mathrm{K}$. Interestingly these are also the micronutrients for which some evidence exists for protection against CVD, although most authors agree that dietary advice should not focus on the individual micronutrients but rather on food sources, such as fruit and vegetables ${ }^{(39-42)}$. In this population, fruit and vegetable intake was less than half the recommended $400 \mathrm{~g}$ of fruit and vegetables per day, even in the urban group. Fruit and vegetables are good sources of dietary fibre, K, folate, antioxidants and minerals such as $\mathrm{Mg}^{(43)}$ and a low intake has been shown to contribute to CVD such as IHD and ischaemic stroke ${ }^{(44)}$. On the other hand, for the other micronutrients, the urban group had median intakes above $100 \%$ of the EAR/AI. In 2003, the South African Department of Health embarked on a National Food Fortification Program, resulting in staple foods such as maize meal and bread flour being fortified with vitamin A, thiamin, riboflavin, niacin, pyridoxine, folic acid, Fe and $\mathrm{Zn}^{(45)}$. Therefore, the bread and maize meal porridge that make up the major component of the diet in this population are fortified, likely explaining the higher intakes of these micronutrients. 
When comparing dietary intakes of the rural and urban participants using predefined DQS, both scores indicated an improved diet quality in the urban participants. The two scores agreed relatively well, although the HDI gave consistently higher values at low scores $(<70 \%$ of the total) and the Adapted Thiele Score consistently higher values at high scores ( $>70 \%$ of the total). This could be due to the fact that they are designed to measure different aspects of diet quality, in that the HDI measures diet quality according to dietary risk for chronic diseases of lifestyle such as CVD (prudency), while the Adapted Thiele Score additionally measures adequacy, as can be seen from the cut-offs used in each score.

An additional factor that may contribute to the discrepancy between the two scores is that the weights of the constituting factors differ between the two scores. In the Adapted Thiele Score micronutrients contribute 1700 of the total 1900 points (100 points allocated for each nutrient), while in the HDI, micronutrient intakes are reflected in only three of the nine components, i.e. dietary fibre, fruit and vegetables, and pulses, nuts and seeds. Therefore in the urban groups, where more participants had micronutrient intakes higher than the EAR/AI, this improved micronutrient intake will result in a larger improvement in the Adapted Thiele Score, in which micronutrient intakes represent a larger portion of the score compared with the HDI. Regardless of the differences between the two DQS discussed above, however, both scores indicated improved diet quality in the urban groups, despite the increased CVD risk, placing doubt on the use of these DQS in this population in relation to CVD risk prevention. On a nutrient level, however, the urban groups also showed 'improved' intakes, with higher micronutrient intakes and although macronutrients were also higher, they were still below CVD prevention guidelines.

A different picture emerges, however, when looking at the results from a different perspective. It is clear that the fat intakes in the urban groups are fast approaching the CVD guideline of $30 \%$ of total energy and also that the intakes of micronutrients with suggested CVD protection were particularly low even in the urban groups. It is therefore possible that without the protective effect of these micronutrients, the $40 \%$ higher fat intakes in the urban groups, despite not being higher than the CVD prevention cut-off, may already result in increased CVD risk factors. Macronutrient guidelines in populations with low micronutrient intakes therefore need to be interpreted with caution and may need to be revisited to take these low intakes into consideration.

Finally, the use of DQS in populations with such low macro- and micronutrient intakes should also be interpreted with caution. The likely reason why the DQS indicated improved diet quality in the urban compared with the rural groups is that the urban groups had higher micronutrient intakes than the rural groups and also when compared with the EAR. From Table 4 it is clear that the median intakes of the urban groups for twelve of the eighteen micronutrients were greater than $100 \%$ while in the rural groups only four were higher. Since the EAR/AI was used as the cut-off values in the Adapted Thiele Score, this would mean more urban participants would have a higher Deficiency Score than the rural participants, as can be seen from the median 17\% higher Deficiency Score of the urban groups. Due to the relatively low fat intakes of this population, however, while intakes were higher in the urban groups, they did not yet reach the CVD cut-off and those participants would therefore not be penalized in the DQS for high fat intakes. This is supported by the small increase in the Excess Score in the urban compared with the rural groups $(0 \cdot 4 \%$ and $2 \%)$. Therefore, the higher micronutrient intake in the urban groups is reflected in the DQS while the higher fat intake is not, resulting in a net higher DQS.

\section{Conclusion}

Urbanization in black South Africans is associated with increased CVD risk, especially in women. Urban men and women had significantly higher intakes of both macro- and micronutrients, with macronutrient intakes well within the recommended CVD guidelines. While micronutrient intakes were generally higher in the urban groups than in the rural groups, intakes of selected micronutrients were disconcertingly low in both groups. Both DQS indicated improved diet quality in the urban groups and good agreement was shown between the scores, although they seemed to measure different aspects of diet quality. When interpreting and selecting DQS, it should be clear how these cut-offs protect against the development of CVD; in other words, if a higher amount of a specific nutrient will protect against (adequacy) or cause (prudency) CVD. When applying predefined DQS in non-Western populations for the purpose of CVD risk prevention, the scores should furthermore be interpreted against the background of the absolute levels of nutrient intakes, how these intakes relate to the cut-offs used and be tailored to the specific population. Current guidelines for prevention of CVD may need to be revisited for populations with low dietary intakes, due to the absence of the protective effect that results from adequate micronutrient intakes.

\section{Acknowledgements}

Sources of funding: This project was funded by the South Africa-Netherlands Research Programme on Alternatives in Development (SANPAD), the South African National Research Foundation (NRF GUN nos. 2069139 and FA2006040700010), North-West University, the Public Health Research Institute and the South African Medical Research Council. Conflicts of interest: The authors have 
declared no conflicts of interest. Authors' contributions: A.K., E.W.-V., M.P., R.C.D. and J.C.J. designed the research; A.K., E.W.-V., M.P. and J.C.J. conducted the research; R.C.D., EW.-V., M.P. and E.J.M.F. analysed the data; R.C.D. and M.P. wrote the paper; R.C.D. and M.P. had primary responsibility for the final content. All authors read and approved the final manuscript. Acknowledgements: The authors would like to thank all participants of the PURE study, as well as the South African PURE research team, field workers and office staff in the Africa Unit for Trans disciplinary Health Research (AUTHeR), North West University, South Africa. They also wish to thank PURE International: Dr S. Yusuf and the PURE project office staff at the Population Health Research Institute, Hamilton Health Sciences and McMaster University, Ontario, Canada.

\section{References}

1. World Health Organization (2009) Global Health Risks. Mortality and Burden of Disease Attributable to Selected Risk Factors. Geneva: WHO; available at http://www. who.int/healthinfo/global_burden_disease/global_health_ risks/en/index.html

2. Hernandez AV, Pasupuleti V, Deshpande A et al. (2012) Effect of rural-to-urban within-country migration on cardiovascular risk factors in low- and middle-income countries: a systematic review. Heart 98, 185-194.

3. Vorster HH (2002) The emergence of cardiovascular disease during urbanisation of Africans. Public Health Nutr 5, 239-243.

4. Steyn K, Sliwa K, Hawken S et al. (2005) Risk factors associated with myocardial infarction in Africa: the INTERHEART Africa study. Circulation 112, 3554-3561.

5. Walker ARP (1955) Diet and atherosclerosis. Lancet 1, 565-566.

6. Bourne LT, Lambert EV \& Steyn K (2002) Where does the black population of South Africa stand on the nutrition transition? Public Health Nutr 5, 157-162.

7. Bjelakovic G, Nikolova D, Gluud LL et al. (2008) Antioxidant supplements for prevention of mortality in healthy participants and patients with various diseases. Cochrane Database Syst Rev issue 2, CD007176.

8. The Alpha-Tocopherol Beta-Carotene Cancer Prevention Study Group (1994) The effect of vitamin E and $\beta$-carotene on the incidence of lung cancer and other cancers in male smokers. N Engl J Med 330, 1029-1035.

9. Omenn GS, Goodman GE, Thornquist MD et al. (1996) Risk factors for lung cancer and for intervention effects in CARET, the Beta-Carotene and Retinol Efficacy Trial. J Natl Cancer Inst 88, 1550-1559.

10. Waijers PM, Feskens EJ \& Ocke MC (2007) A critical review of predefined diet quality scores. Br J Nutr 97, 219-231.

11. Wirt A \& Collins CE (2009) Diet quality - what is it and does it matter? Public Health Nutr 12, 2473-2492.

12. Thiele S, Mensink GB \& Beitz R (2004) Determinants of diet quality. Public Health Nutr 7, 29-37.

13. Huijbregts P, Feskens E, Rasanen L et al. (1997) Dietary pattern and 20 year mortality in elderly men in Finland, Italy, and The Netherlands: longitudinal cohort study. BMJ 315, 13-17.

14. Teo K, Chow CK, Vaz M et al. (2009) The Prospective Urban Rural Epidemiology (PURE) study: examining the impact of societal influences on chronic noncommunicable diseases in low-, middle-, and high-income countries. $\mathrm{Am}$ Heart J 158, 1-7.

15. Pieters M, de Maat MP, Jerling JC et al. (2011) Fibrinogen concentration and its role in CVD risk in black South Africans - effect of urbanisation. Thromb Haemost 106, 448-456

16. Kruger MC, Kruger IM, Wentzel-Viljoen E et al. (2011) Urbanization of black South African women may increase risk of low bone mass due to low vitamin D status, low calcium intake, and high bone turnover. Nutr Res 31, $748-758$

17. Fourie CM, Van Rooyen JM, Kruger A et al. (2012) Soluble urokinase plasminogen activator receptor (suPAR) is associated with metabolic changes in HIV-1-infected Africans: a prospective study. Inflammation 35, 221-229.

18. Wentzel-Viljoen E, Laubscher R \& Kruger A (2011) Using different approaches to asses the reproducibility of a culturally sensitive quantified food frequency questionnaire. S Afr J Clin Nutr 24, 143-148.

19. MacIntyre UE, Venter CS \& Vorster HH (2001) A culturesensitive quantitative food frequency questionnaire used in an African population: 1. Development and reproducibility. Public Health Nutr 4, 53-62.

20. MacIntyre UE, Venter CS \& Vorster HH (2001) A culturesensitive quantitative food frequency questionnaire used in an African population: 2. Relative validation by 7-day weighted records and biomarkers. Public Health Nutr $\mathbf{4}$, 63-71.

21. Venter CS, MacIntyre UE \& Vorster HH (2000) The development and testing of a food portion photograph book for use in an African population. J Hum Nutr Diet 13, 205-218.

22. Langenhoven ML, Conradie PJ \& Wolmarans P (1991) Medical Research Council Food Quantities Manual, 2nd ed. Parow Valley: Medical Research Council.

23. Langenhoven ML, Kruger M, Gouws E et al. (1991) MRC Food Composition Tables, 3rd ed. Parow Valley: Medical Research Council.

24. Kruger M, Sayed N, Langenhoven ML et al. (1998) Composition of South African Foods: Vegetables and Fruit. Supplement to the MRC Food Composition Tables 1991. Parow Valley: Medical Research Council.

25. Sayed N, Frans Y \& Schönfeldt HC (1999) Composition of South African Foods: Milk and Milk Products, Eggs, Meat and Meat Products. Supplement to the MRC Food Composition Tables 1991. Parow Valley: Medical Research Council.

26. Institute of Medicine (1997) Dietary Reference Intakes for Calcium, Phosphorus, Magnesium, Vitamin D and Fluoride. Washington, DC: National Academy Press.

27. Institute of Medicine (1998) Dietary Reference Intakes for Thiamin, Riboflavin, Niacin, Vitamin $B_{6}$, Folate, Vitamin $B_{12}$, Pantothenic Acid, Biotin and Choline. Washington, DC: National Academy Press.

28. Institute of Medicine (2000) Dietary Reference Intakes for Vitamin C, Vitamin E, Selenium and Carotenoids. Washington, DC: National Academy Press.

29. Institute of Medicine (2001) Dietary Reference Intakes for Vitamin A, Vitamin K, Arsenic, Boron, Chromium, Copper, Iodine, Iron, Manganese, Molybdenum, Nickel, Silicon, Vanadium and Zinc. Washington, DC: National Academy Press.

30. Institute of Medicine (2002) Dietary Reference Intakes for Energy, Carbohydrate, Fibre, Fat, Fatty Acids, Cholesterol and Protein and Amino Acids. Washington, DC: National Academy Press.

31. Hann CS, Rock CL, King I et al. (2001) Validation of the Healthy Eating Index with use of plasma biomarkers in a clinical sample of women. Am J Clin Nutr 74, 479-486.

32. Seymour JD, Calle EE, Flagg EW et al. (2003) Diet quality index as a predictor of short-term mortality in the American 
Cancer Society Cancer Prevention Study II Nutrition Cohort. Am J Epidemiol 157, 980-988.

33. Knoops KT, de Groot LC, Kromhout D et al. (2004) Mediterranean diet, lifestyle factors, and 10-year mortality in elderly European men and women: the HALE project. JAMA 292, 1433-1439.

34. World Health Organization (2007) Prevention of Cardiovascular Disease: Guidelines for Assessment and Management of Cardiovascular Risk. Geneva: WHO; available at http://www.who.int/cardiovascular_diseases/publications/ Prevention_of_Cardiovascular_Disease/en/index.html

35. Charlton KE, Steyn K, Levitt NS et al. (2005) Diet and blood pressure in South Africa: intake of foods containing sodium, potassium, calcium, and magnesium in three ethnic groups. Nutrition 21, 39-50.

36. Pisa PT, Kruger A, Vorster HH et al. (2010) Alcohol consumption and cardiovascular disease risk in an African population in transition: the Prospective Urban and Rural Epidemiology (PURE) study. S Afr J Clin Nutr 23, Suppl. 1, S29-S37.

37. Delisle H (2010) Findings on dietary patterns in different groups of African origin undergoing nutrition transition. Appl Physiol Nutr Metab 35, 224-228.

38. MacIntyre UE, Kruger HS, Venter CS et al. (2002) Dietary intakes of an African population in different stages of transition in the North West Province, South Africa: the THUSA study. Nutr Res 22, 239-256.

39. Pereira MA \& Liu S (2003) Types of carbohydrates and risk of cardiovascular disease. J Womens Health (Larchmt) 12, $115-122$.
40. Griffith LE, Guyatt GH, Cook RJ et al. (1999) The influence of dietary and nondietary calcium supplementation on blood pressure: an updated meta analysis of randomized controlled trials. Am J Hypertens 12, 84-92.

41. Ye Z \& Song H (2008) Antioxidant vitamins intake and the risk of coronary heart disease: meta-analysis of cohort studies. Eur J Cardiovasc Prev Rehabil 15, 26-34.

42. D'Elia L, Barba G, Cappuccio FP et al. (2011) Potassium intake, stroke, and cardiovascular disease: a meta-analysis of prospective studies. J Am Coll Cardiol 57, 1210-1219.

43. Bazzano L (2005) Dietary Intake of Fruit and Vegetables and Risk of Diabetes Mellitus and Cardiovascular Disease. Background paper for Joint FAO/WHO Workshop on Fruit and Vegetables for Health, 1-3 September 2004, Kobe, Japan. Geneva: WHO; available at http://www.who.int/ dietphysicalactivity/publications/f\&v_cvd_diabetes.pdf

44. Lock K Pomerleau J, Causer L et al. (2004) Low fruit and vegetable consumption. In Comparative Quantification of Health Risks: Global and Regional Burden of Disease Attributable to Selected Major Risk Factors, pp. 597-728 [M Ezzati, AD Lopez, A Rodgers et al., editors]. Geneva: WHO.

45. Republic of South Africa, Department of Health (2003) Government Notice R504. Foodstuffs, Cosmetics and Disinfectants Act, 1972 (Act No. 54 of 1972). Regulations Relating to the Fortification of Certain Foodstuffs. Government Gazette 7 April 2003, 454, no. 24715, 1-23; available at http://www. info.gov.za/view/DownloadFileAction?id=63394

46. Van Heerden IV \& Parry CDH (2001) If you drink alcohol, drink sensibly. S Afr J Clin Nutr 14, issue 3, S71-S77. 